\title{
Principals as Assessment Leaders in Rural Schools
}

\author{
Patrick Renihan \\ University of Saskatchewan, Canada \\ Brian Noonan \\ University of Saskatchewan, Canada
}

This article reports a study of rural school principals' assessment leadership roles and the impact of rural context on their work. The study involved three focus groups of principals serving small rural schools of varied size and grade configuration in three systems. Principals viewed assessment as a matter of teacher accountability and as a focus for the school professional team. They saw themselves as teachers first, stressing their importance as sources of teacher support, serving a 'buffer role, 'ameliorating external constraints to effective assessment and learning. Bureaucratic environments and trappings of large-scale assessment were seen to be incompatible with the familial nature of rural professional contexts. Other constraints were the logistical challenges of small student populations, higher instances of multi-graded classrooms, and the absence of grade-alike professional interaction. Conversely, smallness enabled professional interaction and transformational leadership. Finally, the quality of system-level support emerged as a critical catalyst for assessment leadership at the school level.

Key Words: principals; teacher accountability; assessment of learning; assessment leadership

One aspect of the assessment reform movement that has not been well researched is its connection to the role of the school principal. It is well known that assessment reform (McMillan, 2001;Stiggins, 2002) has been defined and promoted in a number of ways and with its own lexicon reflecting pedagogical stances and strategic preferences related to such orientations as assessment literacy (Cizek,1995; Fullan, 2001), assessment for learning

(Stiggins, 2001), assessment of learning, (Stiggins,2001); assessment as learning (Earl \& Katz,2006) and large-scale testing. These have become central elements of the principal's mandate (Harris, 2002). One of the concepts that has been used- but not frequently examined- in educational research is that of assessment leadership that we have defined as the role and expectations of formal school leaders in relation to the task of enhancing assessment literacy among school professionals and paraprofessionals (Noonan \& Renihan, 2006). It is also recognized that the role of instructional leader is very much influenced by the context in which the school leader operates. That context may include, for example, the size of the school, the nature of the community, grade levels (early, middle, high school), and the types of students involved (e.g., students with special needs, members of diverse cultural and language groups).

The purpose of this article is to report and discuss the findings of an exploratory study designed to shed light on how principals in rural schools perceive and engage their assessment leadership responsibilities. Particular attention was devoted in this study to the impact of rural contexts upon the instructional leadership and assessment leadership provided by principals. In short the study addressed the following questions:

1) How do principals of rural schools understand what it means to be an assessment leader in rural contexts?

2) To what extent and in what ways does rural school context affect the principal's instructional/assessment leadership role? Why are these questions relevant to rural educational research? In light of recent reforms, the expectations placed upon in-school leaders for enhanced attention to (and accountability for) leadership for learning has been felt by principals throughout the world (Phillips et al. (2003). The impacts of these developments on principals have included an increased demand for new sets of leadership knowledge, leadership appreciations and leadership skills (Noonan \& Renihan, 2006). These include skills of leading professional development, knowledge regarding the use of achievement data in classroom planning, school planning and decisionmaking, and appreciations for the importance of nurturing professional collaboration on matters relating to instruction and student achievement. Meeting these demands presents a challenge for principals everywhere, and the challenge is compounded when the particularities of school context are added to the mix. In the context of rural schools, the issue arises as to the supports available 
to principals, not only in acquiring knowledge, appreciations and skills required of assessment leadership, but using them effectively given the powerful constraints placed upon them by their context.

\section{Meeting School Effectiveness and Instructional Leadership Expectations}

A central assumption underlying this article is that principals make a difference. Over the course of the past ten years, an increasing amount of research evidence has pointed to the central role played by the school principal in student achievement, school effectiveness and school improvement. Many studies across different countries have found evidence of the crucial role that principals can play in improving teaching and learning (Renihan, 2008; Donaldson, 2001; Elmore, 2001; Henchey, 2001; Leithwood, 2000; McLaughlin \& Talbot, 2001; Newmann, King \& Young, 2000; and others.). Gonzales et al. (2002) identified over 60 pertinent studies including theoretical and field research of the principal's impact on student achievement. Fullan (2003) cited improvements in 93 schools in the Toronto District School Board's Early Literacy Project and in the UK's national literacy and numeracy initiative as illustrations of the importance of principal leadership in successful translation and implementation of mandated curricular strategies. Further, following a large scale international study of school effectiveness research, Reynolds \& Teddlie (2000, pp. 141-144) made the observation that leadership is 'centrally synonymous with school effectiveness.'

Specific expectations of principals as assessment leaders have received increasing of attention in the research. Investigations conducted by Stiggins (2001), O’Donnell and White (2005), and Noonan and Renihan (2008) provided useful guidelines for principals involved in assessment leadership. Stiggins (2001), for example, proposed how principals can work toward assessment success. He made the point that, for success in school-based assessment, principals must have: i) clear and appropriate achievement targets and ii) an assessment literate school staff or faculty. Those two conditions establish a basis for the five standards that Stiggins (2001) used as a framework for principals' assessment literacy, namely: i) appropriate achievement expectations for students, ii) assessment that serves instructional purposes, iii) accurately serving the intended purpose, iv) a broad scope of student performances to permit confident conclusions, and, v) elimination of bias that can affect the accuracy of results. Stiggins (2001) added the point that, in order to be effective in assessment leadership, principals need: i) to become assessment literate and, ii) to remove barriers to teachers' assessment literacy.

Other researchers expressed views that provide useful elaboration on the themes outlined by Stiggins. For example, O’Donnell and White (2005) provided a developmental perspective on assessment leadership for principals. In conducting a study of public perceptions of the role of the principal, these researchers drew some conclusions as to factors that can affect the development of principals as assessment leaders. Their work suggests that important skills for development in this regard are i) skills of working with teachers to promote school learning, ii) skills of encouraging collaboration among teachers, particularly in lower socio-economic status schools, and iii) skills of comprehensively assessing their own instructional leadership behaviours. The results of the O'Donnell and White study, though not unique, highlight the importance of principals focusing on their own behaviour as a way to influence teacher development and student achievement.

\section{Assessment Leadership in Rural Contexts}

A significant body of research has focused on the work of principals in rural schools from a variety of perspectives For example, the role of principals in rural settings has been addressed by Browne-

Ferrigano and Allen (2006) who proposed collaborative efforts for school principals involved in high needs rural schools, as have Livingston, Reed, and Good (2001). Others, such as Loveland (2002), have taken a much broader perspective, investigating the challenges and rewards of rural school leadership. Similarly DeRuych (2005) pointed out the importance of strong instructional leadership in contemporary rural schools. In other studies, the role of the principal was found to be such that it creates its own types of stress or anxiety; for example, Buettner (1992) studied the types of coping mechanisms used by principals in rural contexts, and provided a number of observations on the implications for principals who may experience stress in their workplace. Some of the suggestions included but were not limited to: in-service opportunities, frequent and purposeful dialogue, and recognizing the complexity of distress.

Although there is a clear realization of the need for principals to possess leadership skills, it is also recognized that principals require some form of professional development to enhance those skills. For example, Salazar (2007) of the University of Nevada, Las Vegas discussed the results of their study of professional development for rural high 
school principals to enhance leadership skills that can guide school reform and "reach higher standards of student achievement" (p.1). Thus it would seem that, in the context of assessment reform, there is a strong interest in principals' knowledge and skills in relation to assessment leadership. That said, although there is considerable evidence to recognize the importance of strong instructional leadership in rural schools, research-based acknowledgement of the environmental influences upon assessment leadership in these settings remains relatively sparse.

\section{Methods}

The study reported in this article was designed to collect data from practicing rural school principals with respect to what it means to be an assessment leader in rural contexts and in what ways rural school context affects their instructional/assessment leadership roles. Data were collected from three focus groups comprised of rural school principals most of them serving in small rural schools in villages in Western Canada. Participants represented twelve rural schools in three school divisions in a Western Canadian province. The schools ranged in size from very small (less than 50 students) to moderately sized schools (up to 400-500 students). They also varied in their grade configurations, and included high schools, K-12 schools and schools with a variety of grade patterns at the elementary/middle levels.

The primary method chosen for data collection in this study was the focus group method. Vaughn and others (1996) noted that focus groups offer distinct advantages over individual interviews, including their variety and visibility, their compatibility with the qualitative research paradigm, the richness they can add to information on the theme under investigation, the opportunities they provide for dynamic, interactive discussion, and the added possibility they provide for individuals to form and discuss opinions during the process. Vaughn et al. (1996) added that this approach is particularly useful in exploratory research. Given these points, combined with the time efficiencies and economies they provided us in rural contexts where the subjects were geographically dispersed, we considered focus groups to be suitable for our purposes.

The key questions posed to focus group participants (and shared with them prior to the sessions) were as follows:

- How important to you, as principal, are teachers' grading and assessment practices?

- To what extent do teachers' assessment and grading strategies reflect your expectations of teachers' instructional practices?
- To what extent should principals be accountable for the assessment practices of teachers ?

- How should the results of teachers' assessment practices be used by principals or other administrators?

- To what extent has the environment of largescale testing and accountability influenced your role as an instructional leader?

- To what extent have developments in assessment for learning influenced your role as instructional leader?

- What is the effect of a rural context (school size, isolation, distance from central office, available supports etc.) on your role as assessment leaders?

- What are the assessment leadership opportunities presented by the rural context of your schools?

- What are the constraints to assessment leadership presented by the rural context of your schools?

Three focus group sessions were held with groups of principals, and results of the focus group sessions were collated and reviewed to determine major themes and ideas relating to their school/organizational contexts, their teacher contexts and the intricacies of the instructional leadership and assessment-related issues in their schools. Once the interviews were completed they were reviewed and summarized on the basis of recurrent themes or ideas that would provide evidence as to: a) Rural principals' understandings of what it means to be an instructional/assessment leader and, b) their perceptions as to the impact of rural context upon the instructional/assessment leadership role.

Once the focus group interviews were completed, the results of the interviews were collated and reviewed by the researchers to determine what major themes or ideas guided the discussions with respect to assessment-related issues in their schools. The results were reviewed and summarized according to recurrent themes relating to the meanings these principals gave to their assessment leadership roles, and the impacts they believed their rural contexts had on them.

\section{Findings}

Prior to the description and discussion of the findings of this study, a clarification of the nature of the accountability context of these schools and their jurisdictions is necessary. The locus of control and responsibility for education is different for the United States and Canada. In Canada, education has (since Confederation in 1867) remained a provincial rather than a Federal responsibility and in the absence of a federal Ministry or a Federal Bureau of Education (as 
exists in the United States), educational matters across the country have been directed by the individual provincial departments-or ministries-of education. Thus the accountability context for education varies from province to province, with varying degrees of emphasis on assessment for, and assessment of, learning. In the United States, because of the No Child Left Behind initiative, assessment, analysis and alternative uses of related data has become one of the major roles of the principal. In the province where this study was based (Saskatchewan) there has been, over the past ten years, an increasing emphasis on large-scale assessment and data-driven school decision-making, though a 'softer' orientation to accountability with a strong emphasis on AFL (assessment for learning) continues to predominate.

The summary of discussions with the groups of principals in these Western Canadian rural schools is presented below from two perspectives: a) Rural principals' understandings of what it means to be an instructional/assessment leader and, b) their perceptions as to the impact of rural context upon the instructional/assessment leadership role.

Rural principals' understandings of what it means to be an instructional/assessment leader Principals saw their assessment leadership role in various ways. Most agreed that the provision of a clear vision and direction for instruction and assessment throughout the school, and promoting discussion of formative, summative and diagnostic elements of assessment among staff were defining elements of their assessment leadership role. As one participant noted, "there needs to be an assessment culture or philosophy in the school, and teacher strategies should align with that." These principals emphasized the importance of knowing what is happening in classrooms, and having the 'big picture' concerning assessment practices in their building. The general consensus seemed to be that the teacher has to bear significant responsibility for assessment practices. There was reluctance among some principals to micromanage the work of teachers, The majority of these principals noted that, given the contexts of their schools, they play the multiple roles of teacher, manager and supervisor. In regard to their role priorities, some observed that they see themselves as teachers first, and that their orientation to assessment is that it is at its best when managed professionally and collegially rather than bureaucratically.

Another dimension of the principal's role in these contexts was that of support. Principals saw their two most common support functions as expediting relevant professional development based upon teacher-identified instructional and assessment needs, and, simply 'being available' for school professionals. Specifically, several principals emphasized the importance of helping teachers cope with the tasks of balancing multiple grades, coping with the demands of special needs students, responding to cultural differences, and differentiating instruction, often in the absence of the additional paraprofessional and material resources that are available to many of their colleagues in larger schools and urban schools. One principal explained, "I don't want my teachers burnt out and on stress leave. I will do all I can to help them be successful." These principals were quite clear, however, in their belief that teachers should be held accountable for their attention to student assessment practices and their impact upon teaching and learning strategies. In this respect, when it came to issues of assessment, they described themselves as maintaining a fairly delicate balance between ensuring accountability and quality control, on one hand, and nurturing professional empowerment among teachers, on the other.

\section{Principals as Assessment Leaders: Impacts of Rural Contexts}

There are obvious contextual differences between rural and urban school jurisdictions (i.e. distance to school, school/classroom size, transportation, accessibility, etc.). However, the extent to which those factors influence the principal's role as an assessment leader remains less obvious The principals involved in the focus groups did acknowledge that a rural school has some unique features (such as grade patterns, parentinvolvement/values, community roles and expectations) and that in the rural context principals spend considerable time and energy on administrative (school organization) issues and less time on such specific leadership functions as assessment leadership.

In the case of the smaller rural schools, the phenomenon of their getting 'lost in the statistics' of large-scale assessment was identified, and for this reason some principals of smaller schools questioned the value of their involvement in large-scale assessment. For the most part these rural school principals assumed that classroom teachers have the ability and responsibility to implement and utilize current grading and assessment practices. However some of the principals did note that a school's grade configuration will influence some assessment initiatives. For example, the assessment reform movement acknowledges that large-scale assessment is undertaken for specific grade levels (i.e. 5, 8, and 11). This would mean that the large-scale assessment process in a k-6 school would be limited to one grade 
level. Further, assessment implementation could involve three grade levels which is an administratively challenging process in a rural school with small student populations and several multigraded classrooms. Some of our respondents questioned the cultural relevance of some tests. One principal, for example, remarked: "When the Math instrument has Shrek on it, it causes me to ask about the cultural relevance of the test for students from Sudan, the Ukraine etc." Also, in rural schools with populations of Aboriginal students, the compatibility of assessment with Aboriginal learning styles and ways of knowing is an important consideration.

From the discussions with our participants, it was evident that several distinctive facets of the rural context of their schools were seen to have powerful influences upon the ability of individual principals to provide assessment leadership. Our participants were quite clear in pointing out that, while some of the above phenomena represent facets that can facilitate their assessment leadership functions, others serve to seriously constrain them.

\section{Those Facets that Facilitate Assessment Leadership}

- $\quad$ Small school populations present an opportunity for enhanced knowledge of students, leading to greater individualized attention to student learning and assessment needs; as one participant observed, "One thing I look at is that we are small in size, and we know each other well. People feel comfortable coming to see me as instructional leader.'

- More intimate, familial professional cohorts present greater opportunity for the creation of collaborative professional cultures within the school, focused on teaching strategies, assessment literacy and school-wide data-driven decision-making;

\section{Those Facets that Constrain Assessment Leadership}

- Community politics;

- Distance from central office and associated isolation of in-school leaders and classroom professionals from sources of support when dealing with challenging instructional and assessment issues;

- Volume of expectations, paperwork etc

- Lack of collegial support for in-school administrators;

- $\quad$ Lack of mentorship for new in-school administrators;

- Difficulties experienced by principals in balancing the multiple roles and expectations of teaching, administration, and instructional leadership/supervision.

Finally, the role of system administration emerged as a significant force that can influence school-level assessment leadership and assessment literacy (and, consequently, the quality of student learning) for better or worse. Participants in our discussions varied in their assessments of the quality of the support devoted by their respective central office administration to school-level efforts at improving learning; but it became clear during our deliberations that the role of central office leadership is a critical one. In short: where senior administrator guidance and expectations for assessment were seen as clear, where central leadership was perceived to model a commitment to the value of assessment for learning, where tangible support was provided in the form of visible leadership presence, and where there was central commitment to professional development and resource allocation, the quality of assessment literacy was seen to be more focused, better planned and more enthusiastically pursued.

\section{Discussion}

Two tensions appear to present concerns for principals who serve in a contemporary rural school context. These relate to the general demands of accountability on one hand, and the changing leadership role demands presented by assessment reform and classroom assessment practices, on the other.

\section{Demands of Accountability}

Accountability, in the context of our discussions, presented three tensions related to expectations of school principals in rural settings. First, it is wellrecognized that principals in large urban systems are expected to work for and with senior officials in their school jurisdiction. In a rural context where schools may be geographically dispersed and have different grade distributions and enrollments, the principal may need to establish different or unique working relationships with senior officials. Second, teachers' professional development in a rural context can be more difficult for smaller geographically diverse schools but it is still expected that the principal provide guidance for the professional development opportunities for his or her staff. Third, in a rural setting, a high premium is frequently placed upon the ability of principals to work with parents and the community. Though this may not be difficult in some small close-knit communities, if the principal is not a member of the school community it can present significant challenges. This can be particularly true 
when, for example, principals are addressing assessment issues such as large-scale assessment where they are expected to ensure that teachers are accountable for a testing program that has been externally prepared and will be externally reported.

\section{Negotiating New Role Demands.}

Although accountability is a significant element of principals' instructional and assessment leadership, the assessment reform movement has focused on the principals' role related to aspects of classroom assessment that have traditionally been within the teacher's realm of responsibility. It is recognized, increasingly, that the role of the principal is to support teachers in learning, and developing cultures of assessment literacy using concepts such as assessment for learning and assessment as learning as vehicles to enhance classroom and school planning and decision-making. As well, it has become necessary for rural principals to be informed about a wide range of current grading practices which can be difficult to implement in rural schools with differences in enrollment, grade distributions etc. Training and professional development for teachers is more easily delivered in urban settings than in rural settings where the resources and opportunities may be less accessible for teachers. As the results of the focus groups illustrated, assessment leadership includes a wide range of classroom-related assessment concerns for rural school principals, and these undoubtedly require substantial leadership time and commitment. It follows that success in this facet of the principal's role is dependent upon the nature of the supports available for leaders who work in these settings.

In short, then, although assessment is seen as an important issue for rural principals, it should also be noted that rural principals are faced with a number of related issues that characterize leadership in a rural context. In light of this discussion, it is important to ensure that rural principals are provided with the opportunity, the resources and the supports to provide not only assessment leadership as outlined here but also a strong focus on their larger role as instructional leaders.

\section{Some Implications for Action}

Although this study highlighted numerous constraints to the effectiveness of assessment leadership in rural contexts, it should be noted that several of our findings represent themes that have been identified as constraints to principals' effectiveness in a variety of studies and across contexts. In a recent survey of the international research on the role of the principal, for example, Philips, Raham \& Renihan (2003) identified a range of significant barriers to principal efficacy which must be overcome in order to create a culture that supports quality school leadership. Among these were the findings that:

- institutions do not devote sufficient attention to promoting/selecting principal candidates for knowledge and skill related to instructional leadership (Elmore, 2000);

- most of principals' time is spent attending to parent issues, community-related tasks, discipline, and facilities management, allowing for very little time to be devoted to instructional leadership, teaching and learning. Lack of time and excessive managerial demands are the two greatest obstacles for modern principals;

- although there are noteworthy exceptions, principals are seldom properly supported in their leadership role by school districts which have previously expected them to do little more than follow orders, oversee staff, keeping the buses running, and contain problems. In these conditions the school leader often feels isolated, overwhelmed, and powerless to accomplish the job;

- in many instances, the rapid pace of reforms presents principals with incoherent and conflicting goals and inadequate lead time to prepare their school communities for their implementation;

- $\quad$ school system policies and union contracts place limits on the autonomy, flexibility and capacity of the principal to act as a change agent.

These barriers to efficacy resonated throughout the discussions we had with our rural school principals, but our participants can take some solace from the realization that their frustrations are to some extent shared by principals everywhere, even though there is little question that such concerns are exacerbated by the very real concerns of their rural contexts. There seems little question that serious attention to the amelioration of major constraints such as those identified by our participants, would go a long way to enhancing the assessment culture and the quality of learning in these school environments. From our discussions, the central and most promising quality is that of support in its various dimensions.

The rural context presents serious challenges to school professionals as they go about the organization of the learning environment, but from what we have heard and seen, we are convinced that the contextual constraints are far from insurmountable. The policy and action implications of our findings suggest that concerted attention to the articulation of the rural principal's support system would serve these professionals very well in ensuring coherent and consistent leadership for learning. 
Those elements of the support system that would seem to hold most promise in this regard include support for relevant preparation, leadership development, and planned mentorship.

It has been pointed out that school leadership programs generally lag far behind best training practice in other sectors and that no nation has developed the comprehensive and coherent leadership development program necessary to do the job (Tucker \& Codding, 2002);

Even where school leaders require a qualification as an entry point, therefore, the practice of providing financial support and time for individuals to access programs, short courses and training modules relevant to the contexts of their work has considerable merit. Further, the vice principalship as a training ground, and source of support, for the principals' role would seem to be an even greater asset in rural contexts than in others.

Local provision for professional development appropriate to the stages of the principal's career is a responsibility school districts have not taken

\section{References}

Bottoms, G. (2002). Leadership teams build wholeschool buy-in for reform efforts. Schools That Work.

Browne-Ferrigno, T., \& Allen, L.W. (2006). Preparing principals for high-need rural schools: A central office perspective about collaborative efforts to transform school leadership. Journal of Research in Rural Education, 21(1), 1-16.

Buettner, R. (1992). Coping mechanisms used by rural principals. Saskatoon, SK: SSTA Research Centre Report \# 95-13.

Cizek, G. (1995). The big picture in assessment and who ought to have it. Phi Delta Kappan, 86(1), 13-22.

DeRuyck, T. (2005). Identifying and addressing the challenges of the rural principal. Retrieved from http://www.mern.ca/f08papers/DeRuyck.doc

Donaldson, G. (2001) Cultivating leadership in schools: People, purpose and practice. New York: Teachers College Press.

Earl, L., \& Katz, S. (2006). Rethinking classroom assessment with purpose in mind. Winnipeg, Manitoba: The Crown in Right of Manitoba

Elmore, R. (2001) Building a new structure for school leadership. Washington, DC: The Albert Shanker Institute.

Fullan, M. (2001). Leading in a culture of change. San Francisco: Jossey-Bass seriously enough (Tucker \& Codding, 2002); effective practices would include the engagement of sharing arrangements with other boards to coordinate aspects of their leadership development activities; the examination of ways by which financial support can be provided for enhanced professional development of school level leaders; and the utilization of the expertise of experienced principals in the delivery of professional development to beginning principals.

Finally, there is a large and growing body of research evidence pointing to the considerable professional payoffs associated with initiating practices of mentorship among school-level administrators within their systems. The provision of the opportunity and time for beginning principals to interact with their more experienced colleagues has considerable potential as a vehicle for developing assessment leadership capacity, particularly among those who are, or will be, working in rural schools.

Fullan, M. (2003) The moral imperative of school leadership.Toronto, ON: Corwin Press and the Ontario Principals Council.

Gonzalez, M., Glasman, N.S., \& Glasman, L.D. (2002). Daring to link principal preparation programs to student achievement in schools. Leadership and Policy in Schools, 1(3), 265-283.

Henchey, N. (2001) Schools that make a difference: Final report. Twelve Canadian secondary schools in low-income settings. Kelowna, B.C.: Society for the Advancement of Excellence in Education.

Howley, A., \& Pendarvis, E. (2003). Recruiting and retaining rural school administrators. Retrieved from http://www.ericdigests.org/2003-4/ruraladminstrators.html

Leithwood, K. (Ed.). (2000). Understanding schools as intelligent systems (pp.99-124). Stamford, CT: JAI Press.

Livingston, M., Reed, T. \& Good, J.W. (2001). Attitudes of rural school principals toward inclusive practices and placements for students with severe disabilities. Retrieved from http://www.education.uiowa.edu/jrel/fall01/Livin gston_0102.htm

Loveland, E. (2002). Challenges and rewards of rural school leadership. Rural Roots, 3(6), 1, 6-9.

O’Donnell, R., \& White, G. (2005). Within the accountability era: Principal instructional 
eadership behaviors and student achievement. NASSP Bulletin, 89, 56-70.

McLaughlin, M., \& Talbert, J., (2001). Professional communities and the work of high school teaching. Chicago: University of Chicago Press.

McMillan, J. (2001). Classroom assessment: Principles and practices for effective instruction. Toronto: Allyn \& Bacon.

Newman, F., King, B., \& Young, P. (2000). Professional development that addresses school capacity. Paper presented at the annual general meeting of the American Educational Research Association.

Noonan, B. \& Renihan, P. (2008). Building assessment literacy: Perceptions of high school principals. International Electronic Journal for Leadership in Learning.

Noonan, B., \& Renihan, P. (2006). Demystifying assessment leadership. Canadian Journal of Educational Administration and Policy.56, (4.)

Noonan, B., \& Renihan. P. (2009). Student assessment practices in inclusive settings. In Edmunds, A. (Ed.), Leadership for inclusion: A practical guide.UK: Sense.

Phillips, S., Renihan, P., \& Raham, H. (2003). The role of the school principal: Present status and future challenges in managing effective schools. Kelowna, BC: Society for the Advancement of Excellence in Education.
Renihan, P. (2008). One more time: Do principals make a difference? Principal leadership and its relationship to selected qualities of school effectiveness in five schools. Proceedings of the Fifth International Congress on Education, Honolulu, January 8, 2008.

Reynolds, D. (2000). Effective school leadership: The contributions of school effectiveness research. Exeter, UK: University of Exeter School of Education. Retrieved from: http://ncsl.org.uk/index.cfm?pageid=ev_auth_rey nolds

Salazar, P. S. (2007). The professional development needs of rural high school principals: A sevenstate study. The Rural Educator, 28(3), 20-27..

Stiggins, R.J. (2001). The principal's leadership role in assessment. NASSP Bulletin, 85, 13-26. DOI: $10.1177 / 019263650108562103$.

Stiggins, R.J. (2002). Assessment crisis: The absence of assessment for learning. Phi Delta Kappan, 83(10), 758-765.

Tucker, M.S., \& Codding, J.B. (Eds.) (2002). The principal challenge: Leading and managing in an era of accountability. San Francisco, CA: Jossey-Bass.

Vaughn, S., Schumm, J., Sinagub, J. (1996). Focus group interviews in education and psychology. Thousand Oaks, CA: Sage.

\section{About the authors:}

Patrick Renihan is a professor in educational administration and the director of the Saskatchewan Educational Leadership Unit at the University of Saskatchewan in Saskatoon, Canada. His research interests are rural education, the principalship, board/ceo assessment, and school effectiveness.

Brian Noonan is an adjunct professor in the Department of Educational Psychology and Special Education and a professional affiliate in the Department of Educational Administration. His research interests are in educational research and enquiry, instructional psychology, classroom assessment, and educational policy development and evaluation. 